\title{
EDITORIAL
}

\section{Focus on sepsis}

\author{
Morten Hylander Møller ${ }^{1,2^{*}} \mathbb{C}$, Waleed Alhazzani ${ }^{3,4}$ and Manu Shankar-Hari ${ }^{5,6}$
}

C 2019 Springer-Verlag GmbH Germany, part of Springer Nature

Sepsis continues to be an important clinical and research problem within critical care, as highlighted in the most recent literature.

The Surviving Sepsis Campaign bundle was updated in 2018 [1]. It was emphasised that within $1 \mathrm{~h}$ of presentation with sepsis, clinicians should: measure lactate, obtain blood cultures, administer broad-spectrum antimicrobials, begin fluid resuscitation with $30 \mathrm{ml} / \mathrm{kg}$ crystalloids, and apply vasopressors in case of fluid refractory shock. It was recommended that this new sepsis 1-h bundle should be used systematically in emergency departments, wards, and ICUs to reduce the global burden of sepsis [1]. While the 1-h bundle is welcomed and reasonable from a patient perspective, the quality of evidence supporting some individual elements of the bundle is low. A group of international experts representing the European Society of Intensive Care Medicine and the Society of Critical Care Medicine recently highlighted research priorities in the recent Surviving Sepsis Campaign guideline [2]. The top-six research priorities were use of personalised medicine in sepsis, fluid resuscitation, rapid diagnostic tests, empirical antibiotic combination therapy, long-term outcomes, and predictors of organ dysfunction.

The burden of sepsis has been the subject of numerous studies the previous year. In a large German nationwide cohort study, more than one out of four patients admitted to hospital were diagnosed with infection, and infection and sepsis were important causes of hospital and intensive-care unit (ICU) admission and death [3]. In a European observational study, the proportion of patients with sepsis admitted to the ICU remained constant throughout a 10-year period between 2002 and 2012, but disease severity seemed to increase [4]. In a Chinese

*Correspondence: mortenhylander@gmail.com

${ }^{1}$ Department of Intensive Care 4131, Copenhagen University Hospital Rigshospitalet, Blegdamsvej 9, 2100 Copenhagen, Denmark

Full author information is available at the end of the article population-based study, the standardised sepsis-related mortality rate was 67 deaths per 100,000 population, corresponding to more than 1 million sepsis-related deaths in 2015 in China [5]. Despite these alarming numbers and despite an estimated 30 million cases of sepsis and 6 million sepsis-related deaths in the world each year, there seems to be a lack of awareness of sepsis in the public. In a survey of Irish adults, less than 30\% were aware of sepsis; a considerably lower proportion compared to other medical conditions, including myocardial infarction, asthma, and breast cancer [6].

Early identification and prediction of patients at risk of developing sepsis, including sepsis-associated adverse outcomes, are paramount and have been researched extensively. In a multicentre cohort study in emergency departments and ICUs in the UK, discrimination of leukocyte surface biomarkers was assessed [7]. Disappointingly, most of the assessed biomarkers performed poorly and had limited clinical predictive validity. Correspondingly, circulating biomarkers were found to discriminate poorly between patients with and without sepsis, and no combination of biomarkers performed better than CRP alone in a French multicentre cohort study [8].

Despite sound biological plausibility for using intravenous immunoglobulin as adjuvant therapy in sepsis, i.e., altered immunoglobulin and B-lymphocyte homeostasis in sepsis, the quality of evidence for its use is very low with no firm evidence for benefit or harm $[9,10]$. Accordingly, the authors requested that more research is needed prior to using intravenous immunoglobulins as adjuvant therapy in patients with sepsis $[9,10]$.

Another promising intervention which has failed to improve the outcome of patients with sepsis is polymyxin B hemoperfusion [11]. In a post hoc analysis of the EUPHRATES trial, patients with high endotoxin activity had a small, but uncertain, benefit from polymyxin B hemoperfusion [12]. However, as highlighted by an accompanying editorial, the validity and clinical implications of this finding are hypothesis-generating only [13].

\section{Springer}




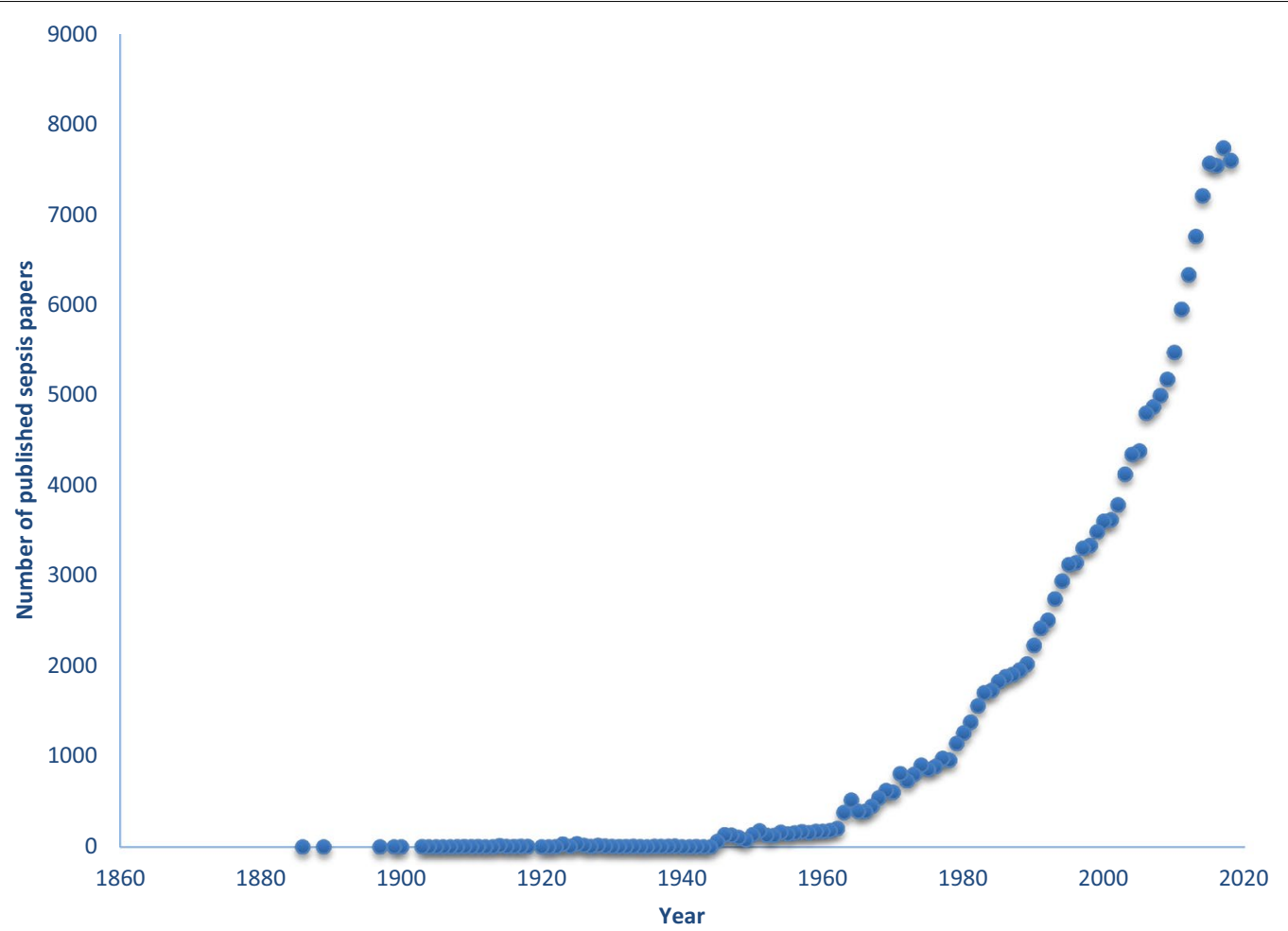

Fig. 1 Number of research papers published according to year of publication in Medline with the search term "sepsis"

Use of vasopressin analogues in distributive shock, including septic shock, has been assessed in several studies the previous year. In a conventional systematic review and meta-analysis, high-quality evidence suggested reduced risk of atrial fibrillation in patients treated with vasopressin and catecholamines, as compared to catecholamines alone [14]. In a Chinese randomised clinical trial of 617 patients with septic shock, no difference in mortality between patients receiving terlipressin versus norepinephrine was observed; however, patients in the terlipressin group experienced more serious adverse events [15]. In a recent individual patient data meta-analysis of four RCTs, the use of vasopressin in patients with septic shock reduced arrhythmias, on the expense of a small increase in the risk of digital ischemia compared to norepinephrine [16].

Following the publication of the ADRENAL and APROCCHSS trials last year-which reported somewhat inconsistent results on the effect of corticosteroids in patients with sepsis-updated systematic reviews and meta-analysis were published [17, 18]. They showed that treatment with corticosteroids does not affect short- or long-term mortality, increases adverse events, but reduces the duration of shock, mechanical ventilation, and ICU admission.

Methodological challenges in septic shock trials have also been discussed in 2018. In a systematic review of septic shock trials, trials reporting statistically significant findings with high control group mortality rates were more likely to be published (publication bias), and there was evidence of significant unexplained heterogeneity in the control groups $[19,20]$. This should be considered when findings from sepsis trials are discussed and interpreted in the critical care community.

In summary, the body of evidence in sepsis research continues to grow, and Fig. 1 illustrates the recent dramatic increase in the number of clinical sepsis papers published.

\section{Author details}

${ }^{1}$ Department of Intensive Care 4131, Copenhagen University Hospital Rigshospitalet, Blegdamsvej 9, 2100 Copenhagen, Denmark. ${ }^{2}$ Centre for Research in Intensive Care, Copenhagen, Denmark. ${ }^{3}$ Department of Health Research Methods, Evidence, and Impact, McMaster University, Hamilton, Canada. ${ }^{4}$ Division of Critical Care, Department of Medicine, McMaster University, Hamilton, Canada. ${ }^{5}$ School of Immunology and Microbial Science, Kings College London, London SE1 9RT, UK. ${ }^{6}$ Guy's and St Thomas' NHS Foundation Trust, ICU Support Offices, St Thomas' Hospital, 1st Floor, East Wing, London SE1 7EH, UK. 


\section{Compliance with ethical standards}

\section{Conflicts of interest}

WA is the methods Chair of the adult and children Surviving Sepsis Campaign Guidelines. MHM is a methodologist in the adult Surviving Sepsis Campaign guideline and a panel member of the children Surviving Sepsis Campaign guideline. MHM and MS-H are on the Editorial Board for ICM and declares no competing interests. All authors are active researchers within the field of sepsis.

\section{Publisher's Note}

Springer Nature remains neutral with regard to jurisdictional claims in published maps and institutional affiliations.

Received: 14 June 2019 Accepted: 24 June 2019

Published online: 2 July 2019

\section{References}

1. Levy MM, Evans LE, Rhodes A (2018) The surviving sepsis campaign bundle: 2018 update. Intensive Care Med 44:925-928

2. Coopersmith CM, De Backer D, Deutschman CS, Ferrer R, Lat I, Machado FR, Martin GS, Martin-Loeches I, Nunnally ME, Antonelli M, Evans LE, Hellman J, Jog S, Kesecioglu J, Levy MM, Rhodes A (2018) Surviving sepsis campaign: research priorities for sepsis and septic shock. Intensive Care Med 44:1400-1426

3. Fleischmann-Struzek C, Mikolajetz A, Schwarzkopf D, Cohen J, Hartog CS, Pletz M, Gastmeier P, Reinhart K (2018) Challenges in assessing the burden of sepsis and understanding the inequalities of sepsis outcomes between National Health Systems: secular trends in sepsis and infection incidence and mortality in Germany. Intensive Care Med 44:1826-1835

4. Vincent JL, Lefrant JY, Kotfis K, Nanchal R, Martin-Loeches I, Wittebole X, Sakka SG, Pickkers P, Moreno R, Sakr Y, Icon Investigators S and Investigators S (2018) Comparison of European ICU patients in 2012 (ICON) versus 2002 (SOAP). Intensive Care Med 44:337-344

5. Weng L, Zeng $X Y$, Yin P, Wang L, Wang CY, Jiang W, Zhou MG, Du B, China Critical Care Clinical Trials G (2018) Sepsis-related mortality in China: a descriptive analysis. Intensive Care Med 44:1071-1080

6. Kerrigan SW, Martin-Loeches I (2018) Public awareness of sepsis is still poor: we need to do more. Intensive Care Med 44:1771-1773

7. Shankar-Hari M, Datta D, Wilson J, Assi V, Stephen J, Weir CJ, Rennie J, Antonelli J, Bateman A, Felton JM, Warner N, Judge K, Keenan J, Wang A, Burpee T, Brown AK, Lewis SM, Mare T, Roy Al, Wright J, Hulme G, Dimmick I, Gray A, Rossi AG, Simpson AJ, Conway Morris A, Walsh TS (2018) Early PREdiction of sepsis using leukocyte surface biomarkers: the ExPRESsepsis cohort study. Intensive Care Med 44:1836-1848

8. Parlato M, Philippart F, Rouquette A, Moucadel V, Puchois V, Blein S, Bedos JP, Diehl JL, Hamzaoui O, Annane D, Journois D, Ben Boutieb M, Esteve L, Fitting C, Treluyer JM, Pachot A, Adib-Conquy M, Cavaillon JM, Misset B, Captain Study G (2018) Circulating biomarkers may be unable to detect infection at the early phase of sepsis in ICU patients: the CAPTAIN prospective multicenter cohort study. Intensive Care Med 44:1061-1070

9. Shankar-Hari M, Madsen MB, Turgeon AF (2018) Immunoglobulins and sepsis. Intensive Care Med 44:1923-1925
10. Welte T, Dellinger RP, Ebelt H, Ferrer M, Opal SM, Singer M, Vincent JL, Werdan K, Martin-Loeches I, Almirall J, Artigas A, Ignacio Ayestaran J, Nuding S, Ferrer R, Sirgo Rodriguez G, Shankar-Hari M, Alvarez-Lerma F, Riessen R, Sirvent JM, Kluge S, Zacharowski K, Bonastre Mora J, Lapp H, Wobker G, Achtzehn U, Brealey D, Kempa A, Sanchez Garcia M, Brederlau J, Kochanek M, Reschreiter HP, Wise MP, Belohradsky BH, Bobenhausen I, Dalken B, Dubovy P, Langohr P, Mayer M, Schuttrumpf J, WartenbergDemand A, Wippermann U, Wolf D, Torres A (2018) Efficacy and safety of trimodulin, a novel polyclonal antibody preparation, in patients with severe community-acquired pneumonia: a randomized, placebo-controlled, double-blind, multicenter, phase II trial (CIGMA study). Intensive Care Med 44:438-448

11. Dellinger RP, Bagshaw SM, Antonelli M, Foster DM, Klein DJ, Marshall JC, Palevsky PM, Weisberg LS, Schorr CA, Trzeciak S, Walker PM, Investigators ET (2018) Effect of targeted polymyxin b hemoperfusion on 28-day mortality in patients with septic shock and elevated endotoxin level: the EUPHRATES randomized clinical trial. JAMA 320:1455-1463

12. Klein DJ, Foster D, Walker PM, Bagshaw SM, Mekonnen H, Antonelli M (2018) Polymyxin B hemoperfusion in endotoxemic septic shock patients without extreme endotoxemia: a post hoc analysis of the EUPHRATES trial. Intensive Care Med 44:2205-2212

13. Pickkers $P$, Russell JA (2019) Treatment with a polymyxin B filter to capture endotoxin in sepsis patients: is there a signal for therapeutic efficacy? Intensive Care Med 45:282-283

14. McIntyre WF, Um KJ, Alhazzani W, Lengyel AP, Hajjar L, Gordon AC, Lamontagne F, Healey JS, Whitlock RP, Belley-Cote EP (2018) Association of vasopressin plus catecholamine vasopressors vs catecholamines alone with atrial fibrillation in patients with distributive shock: a systematic review and meta-analysis. JAMA 319:1889-1900

15. Liu ZM, Chen J, Kou Q, Lin Q, Huang X, Tang Z, Kang Y, Li K, Zhou L, Song Q, Sun T, Zhao L, Wang X, He X, Wang C, Wu B, Lin J, Yuan S, Gu Q, Qian K, Shi X, Feng Y, Lin A, He X, Study Group of I, Guan XD (2018) Terlipressin versus norepinephrine as infusion in patients with septic shock: a multicentre, randomised, double-blinded trial. Intensive Care Med 44:1816-1825

16. Nagendran M, Russell JA, Walley KR, Brett SJ, Perkins GD, Hajjar L, Mason AJ, Ashby D, Gordon AC (2019) Vasopressin in septic shock: an individual patient data meta-analysis of randomised controlled trials. Intensive Care Med 45:844-855

17. Rygard SL, Butler E, Granholm A, Moller MH, Cohen J, Finfer S, Perner A, Myburgh J, Venkatesh B, Delaney A (2018) Low-dose corticosteroids for adult patients with septic shock: a systematic review with meta-analysis and trial sequential analysis. Intensive Care Med 44:1003-1016

18. Lamontagne F, Rochwerg B, Lytvyn L, Guyatt GH, Moller MH, Annane D, Kho ME, Adhikari NKJ, Machado F, Vandvik PO, Dodek P, Leboeuf R, Briel M, Hashmi M, Camsooksai J, Shankar-Hari M, Baraki MK, Fugate K, Chua S, Marti C, Cohen D, Botton E, Agoritsas T, Siemieniuk RAC (2018) Corticosteroid therapy for sepsis: a clinical practice guideline. BMJ 362:k3284

19. de Grooth HJ, Postema J, Loer SA, Parienti JJ, Oudemans-van Straaten HM Girbes AR (2018) Unexplained mortality differences between septic shock trials: a systematic analysis of population characteristics and controlgroup mortality rates. Intensive Care Med 44:311-322

20. de Grooth HJ, Parienti JJ, Postema J, Loer SA, Oudemans-van Straaten HM Girbes AR (2018) Positive outcomes, mortality rates, and publication bias in septic shock trials. Intensive Care Med 44:1584-1585 